\title{
III. Remarks on microscopic chemistry
}

\section{Rev. Edward Craig M.A. F.R.S.E.}

To cite this article: Rev. Edward Craig M.A. F.R.S.E. (1836) III. Remarks on microscopic chemistry, Philosophical Magazine Series 3, 9:51, 10-14, DOI: $10.1080 / 14786443608636443$

To link to this article: http://dx.doi.org/10.1080/14786443608636443

$$
\text { 册 Published online: } 01 \text { Jun } 2009 .
$$

Submit your article to this journal $\pi$

LII Article views: 2

Q View related articles $₫$ 
III. Remarks on Microscopic Chemistry. By the Rev. EDWARD CraIG, M.A., F.R.S.E.*

T $\mathrm{T}$ has been suggested to me that a short notice of some modes which I have adopted for examining under the microscope the phænomena attendant on chemical action, might tend in some degree to facilitate the researches of other and abler men in this department of inquiry. Not that the subject can be regarded as altogether new: after the lengthened and accurate observations of Leeuwenhoeck, Hooke, and others, on minute substances, it is impossible that the particular point to which my attention has been turned can altogether have escaped notice; yet the microscopic investigation of chemical agents in a state of reaction has certainly not occupied attention as much as it seems to merit.

M. Raspail published recently in Paris, a work which he entitles Nouvel Système de Chimie organique, fondé sur des méthodes nouvelles d'Observation. I have met with this work since the origination of my own modes of observation; and it fully justifies the idea, that notwithstanding the long time that the microscope has been in use, it has never been effectively applied to the object in consideration.

M. Raspail's work is a detailed account of the examination of organic structures; and the mode of observation for this purpose on which he lays the most stress, as having a claim to novelty, is the microscopic investigation of the visible effect produced on such structures by chemical agents. "I carry," he says, " the laboratory of the chemist on to the port-objects of the microscope." His very elaborate and valuable treatise closes with a note to the appendix, vindicating the novelty and originality of his modes of observation.

My own observations, conducted by one so much a novice in matters of scientific inquiry, are in themselves necessarily unimportant; they have, however, been carried on independently of any knowledge of $M$. Raspail's work; and they have a different object, in as much as $M$. Raspail confined himself to means for observing a particular class of phænomena. The particular object to which my attention was turned was the adoption of arrangements by which chemical action generally in the minutest visible quantities of substances might be examined.

Some months ago I was led by the statement of Dr. Brown, the eminent scientific botanist, to examine the motion of small molecules of matter floating in water, and excluded from the

- Read before the Royal Society of Edinburgh in December 1834; and now communicated by the Author. 
The Rev. E. Craig's Remarks on Microscopic Chemistry. 11

pressure of the atmosphere: this suggested a further inspection into the form and character of the smallest discoverable particles of any pure chemical precipitates, many of which I found to be circular in the form of their molecular particles. From this the step was made naturally and almost necessarily to the observation of chemical action. The plan adopted for placing very small particles of matter in a floating state of thin film under the microscope, presented also an ample means for submitting to equally accurate scrutiny equally small portions of substances in a state of reaction: a few sentences will detail the plan. The phænomena may in a few cases be described, and then the interminable field of such inquiry will be fully open to any one who delights in the novelty of new modes of scientific research. The veriest tyro and the most advanced chemist will be alike interested in the wonders that open to his view.

The microscope which I use was made by Chevallier of Paris, and is peculiarly well adapted for the purpose. The port-object is a broad brass tablet perforated in the middle to receive reflected light from below, and fitted also with a powerful convex lens to throw light from above. It is steady and firm, which is very desirable. The whole additional apparatus necessary is a number of small plates of thin and very flat glass, filed at the edges to prevent them from cutting the finger, and a few glass rods with small rounded ends for taking up a drop of liquid. The glasses should be free from flaws and fitted to lie closely with even pressure upon one another.

When I wish to examine the action of two substances I lay a plate of glass on the port-object, and put on it a very minute portion of one substance; I adjust this to the focus of the lens in use, and ascertain the form and character of the substance in a quiescent state. I then lengthen the distance of the object-glass from the object a little to prepare for the subsequent observation; for I find that in the use of highpowered lenses the introduction of a second plate of glass alters the focus: and this must be provided for, as one instant lost, after the two chemical agents are in contact, is of importance. I then draw the glass a little aside, and holding in my hand another plate of glass, I put on it the other substance, say a drop of acid. I spread both to an equal extent on their respective glasses, and then quietly and carefully turning down the one upon the other, I push them gently forward, by the application of a fine point to the edge of the lower glass only, to their proper place on the port-object. The upper glass should never be touched after it is turned 


\section{The Rev. E. Craig's Remarks on Microscopic Chemistry.}

down, as it will disturb the action. It should therefore be somewhat smaller in dimension then the lower glass, to diminish the risk of its being moved accidentally. The pressure of the one glass upon the other spreads the whole compound into one nearly uniform film upon one level, and consequently the whole action going on may be examined by gently moving the glass in different directions.

The few experiments which I describe are those of combinations and decompositions with respect to which the results are universally known. 'They are detailed, therefore, only to exemplify the very great facility with which the most minute phænomena attending chemical action can be seen by means of the apparatus described, and which are lost sight of in operating with larger quantities, in the retort or the testtube.

For instance: put on the lower glass a very small portion of carbonate of copper, and on the upper glass a drop of nitric acid, and bring them together. The carbonic acid is seen to evolve in beautiful globules with more or less violence, which gradually merge into each other : the round particles of the carbonate gradually disappear as the solution of the nitrate of copper is formed. A few massy crystals of a deep blue colour appear amongst the remains of the carbonate, whilst in the clear solution multitudes of small rhombic tabular crystals are deposited in all their possible varieties of proportion. Raise the upper glass gently and add a drop of ammonia; the crystals of the nitrate instantly dissolve and disappear. The nitrate of ammonia is spread over the glass in a great variety of forms, and this is interspersed with groups of prisms of the deep violet-coloured ammoniuret of copper.

The phænomena attendant on the production of the chlorochromic acid are equally beautiful. The action of the sulphuric acid on the chloride of sodium for the elimination of the muriatic acid is at first very violent. The whole field becomes turbid with green and red particles rushing onward in different currents. At length it begins to clear. Often from one brighter spot a series of globnles begin to arise, increase, and rush for. ward in one continued course, attended on each side by a multitude of small drops of the chloro-chromic acid; and finally, as the action subsides, a field of clear amber-coloured liquid appears filled with varied crystals of sulphate of soda and sulphate of potash, sprinkled irregularly with the blood-red drops of the acid, and occasionally mixed with cubes of the chloride of sodium and cubes of the bichromate of potash that yet remain undecomposed.

On bringing together the ferrocyanate of potash and sul- 
phate of iron, the process of crystallization is very distinctly observed. Sulphate of potash in solution is at first formed, in which the small particles of the deep Prussian blue float. The course of these coloured particles floating in the colourless fluid exhibits the currents that run in it, and soon the crystallization of the sulphate of potash commences in a variety of characteristic forms, the particles of the pigment indicating the flowing of the tide in which they float, as the solution gradually forms itself into masses of crystallization along the line.

One of the most remarkable changes in the character of crystallization is seen if sulphuric acid be added to carbonate of copper: crystals speedily appear in the form of six-sided tabular prisms. Add a little ammonia ; the form of crystallization is changed entirely to long rectangular prisms with the angles replaced. Add a little more ammonia and the form changes to several varieties of the rhombic octohedron : a little nitric acid restores again the form of the rectangular prism. And in all these successive changes it is not that a few crystals of another form have been superadded, but each time the metamorphosis is seen to take place in the whole mass.

The microscopic history of iodine in the exhibition to it of a variety of agents is most interesting. Its effect as a colouring matier on the oval molecules of starch is very pretty. It is equally curious to see the application of a portion of nitric acid swell those coloured globules from their centre till they are torn by the internal force and dissipated. If solution of iodine be added to sulphate of soda in solution, the result is very beautiful. The alcohol takes up a portion of the water from the sulphate of soda, which consequently crystallizes in long prisms. The iodine deprived of the alcohol appears in cherry-red drops, and in dark rhombic metallic-looking crystals.

It would be easy to multiply instances, but these must suffice as a specimen of the interesting objects that await experiment as the reward of the observer. The range of experiments may easily be extended to those processes which require heat: longer glasses must then be used which reach beyond the edge of the port-object, and a small spirit-lamp applied under the projecting portion of the glass will give any degree of heat required either for evaporation or boiling.

Some curious results also have been observed on the application of the galvanic pile to chemical substances under the microscope. For this purpose it is desirable to use a lens of somewhat smaller power. The observation cannot well be carried on except on a single plate of glass; and the lens used, 


\section{The Rev. E. Craig's Remarks on Microscopic Chemistry.}

therefore, should be of such a focus as to allow of its being above the reach of the vapours that arise, and that would otherwise condense on it and obstruct the view. Some little tact and experience also are required to manage the wires of the battery, because under the compound microscope they appear reversed. I will give an instance or two. When the copper wires were put into a drop of ammonia, a very beautiful greenish foliated or dendritic structure started from the positive pole, and rushed towards the other. On withdrawing the wires a little from each other, a new growth arose out of the extremity of the previous formation, and generally on coming within a certain distance of the negative pole it assumed the metallic lustre.

Galvanic action has been long known to coagulate albumen : on examining this action under the microscope this thicker or white portion showed itself to be a vesicular structure which shrunk up in folds separated in several directions by stronger integuments; while the thin liquid which previously filled them, and gave them in a state of distension complete transparency, spread over the glass dividing and drying in compartments like those of a dragon-fly's wing.

These statements will be ample to put any one in possession of the mode for making similar observations. Further illustrations are unnecessary. The object of this notice is merely to describe a simple arrangement for approaching more nearly the phænomena of chemical action. The microscope will thus open to the chemist new and interminable fields of fascinating inquiry, which cannot but have their use ; for although in this mode of operating the several substances must meet each other in unweighed and indefinite proportions, yet the plan seems to hold out some advantages, at least to facilitate the incipient processes of analysis, and to serve as a guide to subsequent experiments of a more measured kind and on a larger scale. If the observation of results is recorded and classified, they must at last lead the practised observer to more than conjectural conclusions as to what he sees; the visible effects under the action of certain agents will become daily more accurately known, till at length the microscopic examination of any substance will go very far to establish its real character.

N.B. Since this paper was read its author has applied a micrometer to the microscope for measuring the angles of the minutest crystals that appear on the field. A short notice of this appeared in Jameson's Journal. 